\title{
Site-selective Amide Functionalization by Catalytic Azoline Engrafting
}

\author{
Wyatt C. Powell, Garrett E. Evenson, and Maciej A. Walczak* \\ Department of Chemistry, University of Colorado, Boulder, CO 80309, United States \\ *maciej.walczak@colorado.edu
}

\begin{abstract}
Amide activation is a challenging transformation due to the stabilizing effect of the amide group. While enzymes can be considered as prototypical systems that have evolved to achieve high selectivity and specificity, small-molecule catalysts that functionalize the amide group may accommodate a much larger selection of substrates but currently remain scarce. Here, by combining the desired features from both catalytic regimes we designed an artificial cyclodehydratese, a catalytic system for site-selective modification of peptides and natural products by engrafting heterocyclic into their scaffolds. The catalytic system features molybdenum( $\mathrm{VI})$ center that was decorated with a sterically congested tripod ligand. The optimized catalyst can introduce azolines into small molecules, natural products, and oligopeptides with high efficiency and minimal waste. We further demonstrate the utility of the new protocol in direct functionalization of a single amide group in the presence of up to seven other chemically similar positions, and direct conversion into amines and thioamides. This new mechanistic paradigm may address an unmet need for a general method for selective and sustainable functionalization of peptides and natural products.
\end{abstract}

Amides are an abundant functional group common in proteins, peptides, synthetic polymers, myriad natural products and pharmaceuticals. ${ }^{1}$ While methods to form this functionality are well-studied, chemical activation of amides represents a challenge due to harsh conditions required to break this resonancestabilized bond. ${ }^{2,3}$ Furthermore, differentiation between virtually identical positions in oligopeptides and proteins through synthetic means remains unprecedented, and recent advances in amide activation focus on compounds with one amide group and often utilize special substrates with reduced stability. ${ }^{4}$ However, direct conversions of amides into amines, ${ }^{5-8}$ thioamides, ${ }^{9} \mathrm{~N}$-alkyl amides, ${ }^{10,} 11$ and various nitrogencontaining heterocycles in complex substrates ${ }^{12}$ are sought-after transformations due to their synthetic appeal and relevance of the products of these transformations in improving anti-bacterial activity ${ }^{13}$ cell permeability, ${ }^{10}$ structural analysis, ${ }^{14-16}$ and as privileged ligands in asymmetric catalysis (Figure $\left.1 \mathrm{~A}\right) .{ }^{17}$ In addressing this challenge we were drawn to the logic of late-stage modification that allows complex organic molecules and biologics to undergo site- and chemoselective functionalization. ${ }^{18-20}$ Current site-selective strategies for peptide and protein modifications focus on reactions of functional groups located in the sidechains of amino acid but little effort has been devoted to direct transformations of the amide group itself. ${ }^{21}$, ${ }^{22}$ In this respect, cyclodehydratase ${ }^{23}$ - a class of ATP-dependent bacterial enzymes installing azoline groups in ribosomally-synthesized peptides such as thiopeptides through serine, threonine, and cysteine cyclodehydration - can serve as a prototypical catalytic system that can directly modify either amide's carbonyl group or the nitrogen atom (Figure 1B) ${ }^{24}$ Cyclodehydratases achieve their selectivity by binding to a leader peptide within the proximity of the substrate,${ }^{25}$ and a similar logic could be applied to artificial systems where the (sulf)hydryl groups located in the side-chain of amino acid determine the site of amide modification through chelation to a catalyst. This approach would effectively mimic the biosynthetic logic of assembling post-translationally modified peptides and complement current synthetic strategies that feature linear coupling of pre-assembled building blocks (Figure 1B). Here, we describe the development of a siteselective functionalization method of amides promoted by bis-oxo $\mathrm{Mo}(\mathrm{VI})$ catalysts under exceptionally mild conditions producing water as the only by-product. This cyclodehydrative oxygen atom-transfer reaction is suitable for the preparation of five-membered heterocycles with high atom economy and minimal waste. In a broader context, our results demonstrate that the mimicry of enzymatic processes with rationally designed small-molecule catalysts which operate through mechanisms independent of the biosynthetic pathway may offer a promising strategy to streamline structure-activity relationship studies and discovery of small molecules with translational potential.

In our approach to selectively activate amides, oxazolines play a central role either as intermediates or as ultimate products due to electrophilic reactivity at $\mathrm{C} 2 / \mathrm{C} 5$ (Figure $1 \mathrm{C}$ ) ${ }^{26}$ Most established methods to introduce azolines use stoichiometric amounts of highly electrophilic reagents that are incompatible with 
complex peptides and are unable to discriminate between even chemically distinct amides. ${ }^{2}$ Loss of stereochemical integrity and generation of dangerous waste plague the reactions even with simple substrates. In this regard, bis-oxo molybdenum catalysts display a unique ability to selectively activate amides. ${ }^{27,28,29}$ While the earlier catalysts could efficiently promote reactions with simple substrates, they were inefficient due to decomposition and undesired side-reactions. To overcome these limitations, we investigated $\mathrm{N}$-capped tripodal tetradentate ligands 1 hypothesized to extend the lifetime of the catalyst and eliminate non-selective pathways such as dehydroalanine formation (Figure $2 \mathrm{~A}$ ). ${ }^{30}$ Ligands 1 with the general formula $\mathrm{N}_{2} \mathrm{O}_{2}$ contain two phenolic oxygen atoms and a spectator pyridine, which acts as semilabile group opening a coordination site for the incoming substrates. ${ }^{31}$ Figure $2 \mathrm{~A}$ depicts a series of complexes prepared by direct exchange of 1 with $\left[\mathrm{MoO}_{2}(\mathrm{acac})_{2}\right]$ (acac $=$ acetylacetonate). ${ }^{32-35}$ When the reactivity of catalysts 2 was benchmarked against other $\mathrm{Mo}(\mathrm{VI})$ complexes with bidentate ligands (e.g., 6methylpicolinic acid or 8-hydroxyquinoline), they consistently resulted in cleaner conversions. Furthermore, the activity of $\mathbf{2}$ could be modulated by changing the sterics of the pyridine group directly shielding one of the oxo ligand (Figure 2B). While replacing the proton in the ortho position with a methyl group had little effects on the rate of cyclodehydration with 3 (entries 1 and 2), installation of the phenyl group resulted in a two-fold increase ( $\mathbf{2} \mathbf{h}$, entry $\mathbf{8})$. This change of reactivity is a highly desirable feature as it reduces detrimental elimination to dehydroalanine and shortens the reaction time to several hours with a complete consumption of 3 (98\% yield). As expected, catalysts with large groups in the close neighborhood to the metal (e.g., $\mathbf{2 a}$ and $\mathbf{2 b}$ ) are significantly slower in catalyzing cyclodehydration of $\mathbf{3}$, and a beneficial nonlinear effect of substituting the meta-position with a large alkyl substituent $\left(R^{3}\right)$ on the phenoxide group was observed in reactions catalyzed by $\mathbf{2} \mathbf{d}$ and $\mathbf{2 f - 2} \mathbf{h}$. We attribute the increase of reactivity to the changes in the overall structure of the complex as demonstrated by analysis of single crystal $\mathrm{X}$-ray structures of $2 \mathrm{e}$ and 2h (Figure 2A). Both complexes show a distorted octahedral geometry and cis-configuration of the dioxo ligands, but the bond between pyridine nitrogen and molybdenum underwent a small but noticeable elongation $(\sim 0.05 \AA)$, a structural change sufficient to increase the catalytic activity. Furthermore, by adding tert-butyl substituents, solid-state structure of $\mathbf{2 h}$ rearranged into a more closed isomer, which is likely the consequence of crystal packing. The bulky tert-butyl groups at the ortho- $(\mathbf{2 a - 2} \mathbf{b}, \mathbf{2 e})$ and meta-positions (2d, 2f-2h) serve to increase solubility in organic solvents, extend the catalyst's lifetime at elevated temperatures $\left(60-140{ }^{\circ} \mathrm{C}\right)$, and introduce overall flexibility. All complexes $\mathbf{2 a - 2} \mathbf{h}$ are crystalline solids stable at ambient conditions and can be recovered (>85\%) by chromatographic purification after completed cyclodehydration.

Figure 2 depicts examples of cyclizations with small molecules, natural products, and commercial drugs under the optimized conditions with catalyst $\mathbf{2 h}$ and azeotropic removal of water. Simple 5- and 6membered heterocycles 5-9 were formed in excellent yields (68\%-98\%, Figure 2C). Similarly, substituted serine $(10-12,14)$, threonine $(4,13,15)$ and cysteine $(19)$ substrates were readily converted into their corresponding oxazoline and thiazoline heterocycles. Even azolines prone to facile epimerization such as conjugate (16) and di-phenyl (17) oxazolines could be formed with no loss of stereochemical integrity under the optimized conditions. The transformation of D-glucosamine hemiacetal represents a direct synthesis of a valuable glycosyl donor 18 that can be incorporated into chemoenzymatic synthesis of $N$-linked glycans. ${ }^{36}$ In some cases, more polar co-solvents such as 1,4-dioxane or $\mathrm{PhCl}$ were added to ensure full solubility of the substrates, but the inhibitory effects of potentially coordinating solvents such as $\mathrm{N}, \mathrm{N}$-dimethylformamide (DMF), dimethylsulfoxide (DMSO), $N$-methylpyrrolidone (NMP) on the reaction rates were significant, and these solvents were not pursued further. Taken together, the direct method offers an entry into a valuable class of heterocycles that can be converted into aromatic thia- or oxazoles, a structural motif that is relevant towards modification of bioactive natural products and commercial drugs. ${ }^{37}$

Several complex substrates for site-selective cyclodehydration are noteworthy of a detailed analysis (Figure 2D). Commercial amides such as bactericidal antibiotic florfenicol ${ }^{38}(20)$ and a gap-junction modulator tonabersat ${ }^{39}(21)$ represent a subset of substrates with one available site for amide activation. In the case of a small-molecule inhibitor of MEK1/2, pirmasertib, ${ }^{40}$ only the conjugated oxazoline 22 was formed. On the other hand, the reaction with chloramphenicol ${ }^{41}$ represents a unique example demonstrating the control of regioselectivity in competing cyclodehydrations between alcohols in different steric arrangements resulting in a 2.3:1 ratio of $\mathbf{2 3}$ with the preference toward a more substituted oxazoline $\mathbf{2 3 b}$ derived from the secondary alcohol. We also note that compound 23b did not equilibrate under the reaction conditions in the absence of catalyst, but a 93:7 mixture of 23a:23b was formed upon heating 23a under the reaction 
conditions for $48 \mathrm{~h}$. This suggests that isomerization is catalyzed by $2 \mathrm{~h}$ and supports the notion that the cyclodehydration proceeds under the kinetic control. Other substrates with basic sites that may render the cyclization prohibitively slow such as aminonucleoside antibiotic puromycin ${ }^{42}(\mathbf{2 4})$ or HIV protease inhibitors indinavir $^{43}(25)$ and lopinavir ${ }^{44}(26)$ underwent cyclodehydrations in consistently high yields. The reaction with paclitaxel ${ }^{45}(27)$, a potent anti-cancer agent, represents another extreme example of high regioselectivity and functional group compatibility in a substrate containing a number of potentially reactive functionalities prone to elimination such as esters, alcohols, and a strained oxetane ring that might react with Lewis acids. Indeed, attempted cyclodehydration of paclitaxel with a highly electrophilic phosphonium salt (the Hendrickson reagent) ${ }^{46}$ or Deoxo-Fluor (bis(2-methoxyethyl)aminosulfur trifluoride) ${ }^{47}$ afforded $<5 \%$ of 27 (based on LC analysis) along with several unidentified products showing loss of water. Cyclization of a narrow-spectrum antibiotic lincomycin demonstrates also that the resultant oxazoline can undergo intramolecular opening with a neighboring alcohol to form an ether as shown in 28.

In addition to small organic molecules, we were interested in testing the efficiency of cyclization with peptide substrates (Figure 3). In the attempt to engraft a small azoline ring onto the macrocycle through direct cyclodehydration, the overall conformation of the macrocycle and arrangement of substituents around the amide of interest need to be considered. Furthermore, some amide bonds may be engaged in intramolecular $\mathrm{H}$-bonding contributing to an even more challenging transformation. ${ }^{48}$ With these considerations in mind, we selected curacycline B (29), ${ }^{49}$ a cyclic peptide with immunomodulary activities, as a model system. The individual serine group in $\mathbf{2 9}$ could be directly converted into $\beta$-chloroalanine $\mathbf{3 0}$, $\beta$-azidoalanine $\mathbf{3 1}$ and mutated into $S$-phenylcysteine $\mathbf{3 2}$ through a common azoline intermediate formed by Mo-catalyzed cyclodehydration and opened with $\mathrm{HCl}, \mathrm{TMSN}_{3}$, and $\mathrm{PhSH}$, respectively. We note that in all transformations presented in Figure $3 \mathrm{~A}$ no epimerization at any potentially susceptible positions was observed.

The following three transformations also showcase the power of site-selective direct amide functionalization: (A) A one-pot mutation of carbonyl group into thioamide $\mathbf{3 3}$ was achieved by exposing oxazoline to $\mathrm{H}_{2} \mathrm{~S}$ and produced 33 in $85 \%$ yield; (B) Regioselective reduction of 29 into amine $\mathbf{3 4}$ was accomplished with a borohydride; and $(C)$ the azoline intermediate was oxidized directly into oxazole 35 albeit in a low yield, which represents a direct conversion of serine into a fully aromatic ring. We next applied the same protocol to site-selectively convert two cyclic peptides - dianthin $\mathrm{G}(36)^{50,51}$ and pseudostellarin $\mathrm{G}(37)^{52}$ into thioamides in the presence of seven or five other amide groups that remained intact during the entire process (Figure 3B). This protocol adds to the palette of methods for carbonyl thionation but also offers high regioselectivity not available with other thiophosphorus reagets. ${ }^{53}$ The molybdenum catalyst $\mathbf{2 h}$ enabled the synthesis of a series of azoline-containing cyclic peptides through direct cyclodehydration of the parent macropeptide with concomitant removal of two $(\mathbf{3 8})$ or even three $(\mathbf{3 9}, \mathbf{4 0})$ molecules of water. The cyclization reactions are not restricted to oxazolines, and two thiazoline groups could be readily installed, as shown in the synthesis of $\mathbf{4 0 .}$

High selectivities and exceptional substrate scope prompted us to undertake mechanistic investigations summarized in Figure 4. In the proposed mechanism, the spectator pyridine ligand in $\mathbf{4 1}$ opens a site for binding of amide $\mathbf{4 2}$ to molybdenum complex 41 (Figure 4A). The catalyst likely "samples" various amide positions and establishes bidentate configuration 43 with $\mathrm{N}-\mathrm{H}$ bonding that can assist in rotation of the amide group into the required conformation for 5-exo-trig cyclization resulting in oxazolidine/thiazolidine 45. The pyridine ring in this step plays an important role of a proton carrier from the $\mathrm{N}-\mathrm{H}$ to the carbonyl's oxygen atom and reorganization into another $\mathrm{H}$-bonded intermediate $\mathbf{4 6}$, which then releases oxazoline 48 and a molecule of water. This proposal is consistent with reactions of ${ }^{18} \mathrm{O}=\mathrm{C}$-labelled amides $\left(95 \%{ }^{18} \mathrm{O}\right.$ incorporation) catalyzed by $\mathbf{2 h}$, which furnished the expected azolines together with recovered molybdenum catalyst $\mathbf{2 h}$ with $<5 \%$ incorporation of ${ }^{18} \mathrm{O}$ as confirmed by high-resolution mass-spectrometry analysis (for details, see SI). This data shows that the oxo ligands may play a role maintaining high Lewis-acidic character of Mo but remain intact throughout the entire catalytic cycle. Along similar lines, Hammett analysis of cyclodehydration of substituted benzamides $\mathbf{4 9}$ with first-order kinetics revealed accumulation of negative charge at the carbonyl group (Figure 4B). This result is supportive of with the hypothesis that breakage of the carbonyl group through addition of a nucleophile is the rate-determining step (conversion of $\mathbf{4 3}$ into $\mathbf{4 5}$ ). 
The mechanism of Mo-catalyzed cyclodehydration was also probed computationally. We first evaluated four representative structures that correspond to complexes $\mathbf{2}$ based on the available crystallographic data (Figure 4C). Bis-oxo complexes 2 exist in two distinct and stable conformers schematically depicted as $\mathrm{Z}(\mathrm{N})$ (where two phenolic arms of the tripod ligand face the pyridine group) and $Z(O)$ (where both the phenoxide groups are located closer the oxo group). Regardless of the substitution of the phenolic group, the $\mathrm{Z}(\mathrm{N})$ structures are more stable $\left(\Delta G\right.$ 9.3-11.7 kcal $\left.\cdot \mathrm{mol}^{-1}\right)$, but their relative stabilities vary depending on the size of the $\mathrm{R}^{1}$ group located on the spectator pyridine ligand. The calculated barriers for interconversion of these structures are low $\left(\Delta G^{\#} 1.2-2.4 \mathrm{kcal} \cdot \mathrm{mol}^{-1}\right)$, and at the reaction conditions, both conformers are readily available. This unique feature allows for accommodation of a broad selection of substrates as the catalyst can adopt optimal conformation in response to the geometry of the reactants. Next, we analyzed the reaction profile with model amides 51 and the $Z(N)$ isomer of 52 (Figure 4D). The removal of water from amides is a thermodynamically unfavorable process that requires at least two challenging steps to take place: rotation to an amide with $Z$ configuration and breakage of the carbonyl group. The DFT study supports the notion that the pyridine group can help to recruit the substrates to bind to the molybdenum center (53 and 54), but in the reactive conformer $\mathbf{5 5}$ that undergoes cyclization the assistance of pyridine moiety is not required. Furthermore, intermediate $\mathbf{5 5}$ shows favorable enthalpic binding $\left(1.3-2 \mathrm{kcal} \cdot \mathrm{mol}^{-1}\right)$ which is sufficient to overcomes the barrier for amide rotation and supports the notion that two binding sites in the substrates are required for cyclization. It is also intriguing to note that the most stable structure $\mathbf{5 5}$ originates from hydrogen bonding between $\mathrm{OH} / \mathrm{SH}$ groups and one of the phenolic ligands. Subsequent steps lead to two intermediates $\mathbf{5 6}$ and $\mathbf{5 7}$ that are stabilized by pyridine and the oxo ligand. From these two structures, the loss of water can proceed with the assistance of catalyst scaffolding (e.g., pyridine) but can also take place after dissociation of oxazolidine/thiazolidine from molybdenum.

In sum, we described a catalytic cyclodehydration process suitable for direct site-selective editing of small molecules, drugs, and peptides. This reaction is characterized by exceptional mildness and generality, and enables introduction of various amide modifications.

Accession codes. CCDC 2108077- 2108078 contain the supplementary crystallographic data for this paper. These date can be obtained free of charge via www.ccdc.cam.ac.uk/data_request/cif.

Acknowledgements. This work was supported by the National Institutes of Health (R01GM138682) and the University of Colorado Boulder. Computational resources from the University of Colorado Boulder Research Computing Group were supported by the National Science Foundation (ACl-1532235 and ACl1532236), the University of Colorado Boulder, and Colorado State University.

Author contributions. W.P. designed the experiments, collected and analyzed the data, wrote the manuscript and supplementary files. G. E. collected and analyzed the data. M. W. conceived and oversaw the project, secured external funding, analyzed the data, and wrote the manuscript and supplementary files. All authors approved the final version.

\section{References}

1. Brown, R. S., The Amide Linkage: Structural Significance in Chemistry, Biochemistry, and Materials Science. John Wiley \& Sons: Hoboken, 2000.

2. Kaiser, D.; Bauer, A.; Lemmerer, M.; Maulide, N., Amide activation: an emerging tool for chemoselective synthesis. Chem. Soc. Rev. 2018, 47, 7899-7925.

3. Chaudhari, M. B.; Gnanaprakasam, B., Recent Advances in the Metal-Catalyzed Activation of Amide Bonds. Chem. Asian J. 2019, 14, 76-93.

4. Li, G.; Ma, S.; Szostak, M., Amide Bond Activation: The Power of Resonance. Trends Chem. 2020, 2, 914-928.

5. Smith, A. M.; Whyman, R., Review of Methods for the Catalytic Hydrogenation of Carboxamides. Chem. Rev. 2014, 114, 5477-5510.

6. $\quad$ Addis, D.; Das, S.; Junge, K.; Beller, M., Selective Reduction of Carboxylic Acid Derivatives by Catalytic Hydrosilylation. Angew. Chem. Int. Ed. 2011, 50, 6004-6011.

7. Werkmeister, S.; Junge, K.; Beller, M., Catalytic Hydrogenation of Carboxylic Acid Esters, Amides, and Nitriles with Homogeneous Catalysts. Org. Process Res. Dev. 2014, 18, 289-302. 
8. Chardon, A.; Morisset, E.; Rouden, J.; Blanchet, J., Recent Advances in Amide Reductions. Synthesis 2018, 50, 984-997.

9. Jagodziński, T. S., Thioamides as Useful Synthons in the Synthesis of Heterocycles. Chem. Rev. 2003, 103, 197-228.

10. Chatterjee, J.; Rechenmacher, F.; Kessler, H., N-Methylation of Peptides and Proteins: An Important Element for Modulating Biological Functions. Angew. Chem. Int. Ed. 2013, 52, 254-269.

11. Bockus, A. T.; Schwochert, J. A.; Pye, C. R.; Townsend, C. E.; Sok, V.; Bednarek, M. A.; Lokey, R. S., Going Out on a Limb: Delineating The Effects of $\beta$-Branching, N-Methylation, and Side Chain Size on the Passive Permeability, Solubility, and Flexibility of Sanguinamide A Analogues. J. Med. Chem. 2015, 58, 7409-7418.

12. Alvarez-Builla, J.; Vaquero, J. J.; Barluenga, J., Front Matter. In Modern Heterocyclic Chemistry, Wiley, 2011; pp I-XIX.

13. Crowley, B. M.; Boger, D. L., Total Synthesis and Evaluation of $\left[\Psi\left[\mathrm{CH}_{2} \mathrm{NH}\right] T p g 4\right]$ Vancomycin Aglycon: Reengineering Vancomycin for Dual d-Ala-d-Ala and d-Ala-d-Lac Binding. J. Am. Chem. Soc. 2006, 128, 2885-2892.

14. Goldberg, J. M.; Batjargal, S.; Chen, B. S.; Petersson, E. J., Thioamide Quenching of Fluorescent Probes through Photoinduced Electron Transfer: Mechanistic Studies and Applications. J. Am. Chem. Soc. 2013, 135, 18651-18658.

15. Chatterjee, J.; Gilon, C.; Hoffman, A.; Kessler, H., N-Methylation of Peptides: A New Perspective in Medicinal Chemistry. Acc. Chem Res. 2008, 41, 1331-1342.

16. Jwad, R.; Weissberger, D.; Hunter, L., Strategies for Fine-Tuning the Conformations of Cyclic Peptides. Chem. Rev. 2020, 120, 9743-9789.

17. Hargaden, G. C.; Guiry, P. J., Recent Applications of Oxazoline-Containing Ligands in Asymmetric Catalysis. Chem. Rev. 2009, 109, 2505-2550.

18. Hong, B.; Luo, T.; Lei, X., Late-Stage Diversification of Natural Products. ACS Cent. Sci. 2020, 6, 622-635.

19. Czerwiński, P. J.; Furman, B., Reductive Functionalization of Amides in Synthesis and for Modification of Bioactive Compounds. Front. Chem. 2021, 9, 655849.

20. Romero, E.; Jones, B. S.; Hogg, B. N.; Rué Casamajo, A.; Hayes, M. A.; Flitsch, S. L.; Turner, N. J.; Schnepel, C., Enzymatic Late-Stage Modifications: Better Late Than Never. Angew. Chem. Int. Ed. 2021, 60, 16824-16855.

21. Hoyt, E. A.; Cal, P. M. S. D.; Oliveira, B. L.; Bernardes, G. J. L., Contemporary approaches to siteselective protein modification. Nat. Rev. Chem. 2019, 3, 147-171.

22. Xu, L.; Kuan, S. L.; Weil, T., Contemporary Approaches for Site-Selective Dual Functionalization of Proteins. Angew. Chem. Int. Ed. 2021, 60, 13757-13777.

23. Dunbar, K. L.; Melby, J. O.; Mitchell, D. A., YcaO domains use ATP to activate amide backbones during peptide cyclodehydrations. Nat. Chem. Biol. 2012, 8, 569-575.

24. Arnison, P. G.; Bibb, M. J.; Bierbaum, G.; Bowers, A. A.; Bugni, T. S.; Bulaj, G.; Camarero, J. A.; Campopiano, D. J.; Challis, G. L.; Clardy, J.; Cotter, P. D.; Craik, D. J.; Dawson, M.; Dittmann, E.; Donadio, S.; Dorrestein, P. C.; Entian, K.-D.; Fischbach, M. A.; Garavelli, J. S.; Göransson, U.; Gruber, C. W.; Haft, D. H.; Hemscheidt, T. K.; Hertweck, C.; Hill, C.; Horswill, A. R.; Jaspars, M.; Kelly, W. L.; Klinman, J. P.; Kuipers, O. P.; Link, A. J.; Liu, W.; Marahiel, M. A.; Mitchell, D. A.; Moll, G. N.; Moore, B. S.; Müller, R.; Nair, S. K.; Nes, I. F.; Norris, G. E.; Olivera, B. M.; Onaka, H.; Patchett, M. L.; Piel, J.; Reaney, M. J. T.; Rebuffat, S.; Ross, R. P.; Sahl, H.-G.; Schmidt, E. W.; Selsted, M. E.; Severinov, K.; Shen, B.; Sivonen, K.; Smith, L.; Stein, T.; Süssmuth, R. D.; Tagg, J. R.; Tang, G.-L.; Truman, A. W.; Vederas, J. C.; Walsh, C. T.; Walton, J. D.; Wenzel, S. C.; Willey, J. M.; van der Donk, W. A., Ribosomally synthesized and posttranslationally modified peptide natural products: overview and recommendations for a universal nomenclature. Nat. Prod. Rep. 2013, 30, 108-160.

25. Dong, S.-H.; Liu, A.; Mahanta, N.; Mitchell, D. A.; Nair, S. K., Mechanistic Basis for Ribosomal Peptide Backbone Modifications. ACS Centr. Sci. 2019, 5, 842-851.

26. McIntosh, J. A.; Donia, M. S.; Schmidt, E. W., Ribosomal peptide natural products: bridging the ribosomal and nonribosomal worlds. Nat. Prod. Rep. 2009, 26, 537-559.

27. Sakakura, A.; Kondo, R.; Ishihara, K., Molybdenum Oxides as Highly Effective Dehydrative Cyclization Catalysts for the Synthesis of Oxazolines and Thiazolines. Org. Lett. 2005, 7, 1971-1974.

28. Sakakura, A.; Kondo, R.; Umemura, S.; Ishihara, K., Dehydrative cyclization of serine, threonine, and cysteine residues catalyzed by molybdenum(VI) oxo compounds. Tetrahedron 2009, 65, 2102-2109. 
29. Akasapu, S.; Hinds, A.; Powell, W.; Walczak, M., Total Synthesis of Micrococcin P1 and Thiocillin I Enabled by Mo(VI) Catalyst. Chem. Sci. 2019, 10, 1971-1975.

30. Wichmann, O.; Sillanpää, R.; Lehtonen, A., Structural properties and applications of multidentate $[\mathrm{O}, \mathrm{N}, \mathrm{O}, \mathrm{X}]$ aminobisphenolate metal complexes. Coord. Chem. Rev. 2012, 256, 371-392.

31. Hossain, M. K.; Haukka, M.; Sillanpää, R.; Hrovat, D. A.; Richmond, M. G.; Nordlander, E.; Lehtonen, A., Syntheses and catalytic oxotransfer activities of oxo molybdenum(vi) complexes of a new aminoalcohol phenolate ligand. Dalton Trans. 2017, 46, 7051-7060.

32. Wong, Y.-L.; Tong, L. H.; Dilworth, J. R.; Ng, D. K. P.; Lee, H. K., New dioxo-molybdenum(VI) and -tungsten $(\mathrm{VI})$ complexes with $\mathrm{N}$-capped tripodal $\mathrm{N} 2 \mathrm{O} 2$ tetradentate ligands: Synthesis, structures and catalytic activities towards olefin epoxidation. Dalton Trans. 2010, 39, 4602-4611.

33. Hinshaw, C. J.; Peng, G.; Singh, R.; Spence, J. T.; Enemark, J. H.; Bruck, M.; Kristofzski, J.; Merbs, S. L.; Ortega, R. B.; Wexler, P. A., Molybdenum(VI)-dioxo complexes with linear and tripodal tetradentate ligands: models for the molybdenum( $\mathrm{VI} / \mathrm{V})$ centers of the molybdenum hydroxylases and related enzymes. 1. Syntheses and structures. Inorg. Chem. 1989, 28, 4483-4491.

34. Wong, Y.-L.; Yan, Y.; S. H. Chan, E.; Yang, Q.; C. W. Mak, T.; K. P. Ng, D., cis-Dioxo-tungsten(VI) and -molybdenum $(\mathrm{VI})$ complexes with $\mathrm{N} 2 \mathrm{O} 2$ tetradentate ligands: synthesis, structure, electrochemistry and oxo-transfer properties. J. Chem. Soc., Dalton Trans. 1998, 3057-3064.

35. Lehtonen, A.; Wasberg, M.; Sillanpää, R., Dioxomolybdenum(VI) and -tungsten(VI) complexes with tetradentate aminobis(phenol)s. Polyhedron 2006, 25, 767-775.

36. Fairbanks, A. J., Synthetic and semi-synthetic approaches to unprotected N-glycan oxazolines. Beilstein J. Org. Chem. 2018, 14, 416-429.

37. Jin, Z., Muscarine, imidaozle, oxazole and thiazole alkaloids. Nat. Prod. Rep. 2013, 30, 869-915.

38. Syriopoulou, V. P.; Harding, A. L.; Goldmann, D. A.; Smith, A. L., In vitro antibacterial activity of fluorinated analogs of chloramphenicol and thiamphenicol. Antimicrob. Agents Chemother. 1981, 19, 294297.

39. Kim, Y.; Griffin, J. M.; Nor, M. N. M.; Zhang, J.; Freestone, P. S.; Danesh-Meyer, H. V.; Rupenthal, I. D.; Acosta, M.; Nicholson, L. F. B.; O'Carroll, S. J.; Green, C. R., Tonabersat Prevents Inflammatory Damage in the Central Nervous System by Blocking Connexin43 Hemichannels. Neurotherapeutics 2017, 14, 1148-1165.

40. Kim, K.; Kong, S.-Y.; Fulciniti, M.; Li, X.; Song, W.; Nahar, S.; Burger, P.; Rumizen, M. J.; Podar, K.; Chauhan, D.; Hideshima, T.; Munshi, N. C.; Richardson, P.; Clark, A.; Ogden, J.; Goutopoulos, A.; Rastelli, L.; Anderson, K. C.; Tai, Y.-T., Blockade of the MEK/ERK signalling cascade by AS703026, a novel selective MEK1/2 inhibitor, induces pleiotropic anti-myeloma activity in vitro and in vivo. Br. J. Haematol. 2010, 149, 537-549.

41. Pongs, O., Chloramphenicol. In Mechanism of Action of Antibacterial Agents, Hahn, F. E., Ed. Springer Berlin Heidelberg: Berlin, Heidelberg, 1979; pp 26-42.

42. Nathans, D., Puromycin Inhibition of Protein Synthesis: Incorporation of Puromycin Into Peptide Chains. Proc. Natl. Acad. Sci. 1964, 51, 585-592.

43. Plosker, G. L.; Noble, S., Indinavir. Drugs 1999, 58, 1165-1203.

44. Croxtall, J. D.; Perry, C. M., Lopinavir/Ritonavir. Drugs 2010, 70, 1885-1915.

45. Alqahtani, F. Y.; Aleanizy, F. S.; El Tahir, E.; Alkahtani, H. M.; AlQuadeib, B. T., Chapter Three Paclitaxel. In Profiles of Drug Substances, Excipients and Related Methodology, Brittain, H. G., Ed. Academic Press, 2019; Vol. 44, pp 205-238.

46. You, S. L.; Razavi, H.; Kelly Jeffery, W., A Biomimetic Synthesis of Thiazolines Using Hexaphenyloxodiphosphonium Trifluoromethanesulfonate. Angew. Chem. Int. Ed. 2003, 42, 83-85.

47. Phillips, A. J.; Uto, Y.; Wipf, P.; Reno, M. J.; Williams, D. R., Synthesis of Functionalized Oxazolines and Oxazoles with DAST and Deoxo-Fluor. Org. Lett. 2000, 2, 1165-1168.

48. Rezai, T.; Bock, J. E.; Zhou, M. V.; Kalyanaraman, C.; Lokey, R. S.; Jacobson, M. P., Conformational Flexibility, Internal Hydrogen Bonding, and Passive Membrane Permeability: Successful in Silico Prediction of the Relative Permeabilities of Cyclic Peptides. J. Am. Chem. Soc. 2006, 128, 1407314080.

49. Auvin, C.; Baraguey, C.; Blond, A.; Lezenven, F.; Pousset, J.-L.; Bodo, B., Curcacycline B, a cyclic nonapeptide from Jatropha curcas enhancing rotamase activity of cyclophilin. Tetrahedron Lett. 1997, 38, 2845-2848. 
50. Amso, Z.; Kowalczyk, R.; Park, Y.-E.; Watson, M.; Lin, J.-m.; Musson, D. S.; Cornish, J.; Brimble, M. A., Synthesis and in vitro bone cell activity of analogues of the cyclohexapeptide dianthin G. Org. Biomol. Chem. 2016, 14, 6231-6243.

51. Tong, Y.; Luo, J.-G.; Wang, R.; Wang, X.-B.; Kong, L.-Y., New cyclic peptides with osteoblastic proliferative activity from Dianthus superbus. Bioorg. Med. Chem. Lett. 2012, 22, 1908-1911.

52. Morita, H.; Kobata, H.; Takeya, K.; Itokawa, H., Pseudostellarin G, a new tyrosinase inhibitory cyclic octapeptide from Pseudostellaria heterophylla. Tetrahedron Lett. 1994, 35, 3563-3564.

53. Ozturk, T.; Ertas, E.; Mert, O., Use of Lawesson's Reagent in Organic Syntheses. Chem. Rev. 2007, 107, 5210-5278. 
A. Amide Modifications and Their Role in Representative Examples

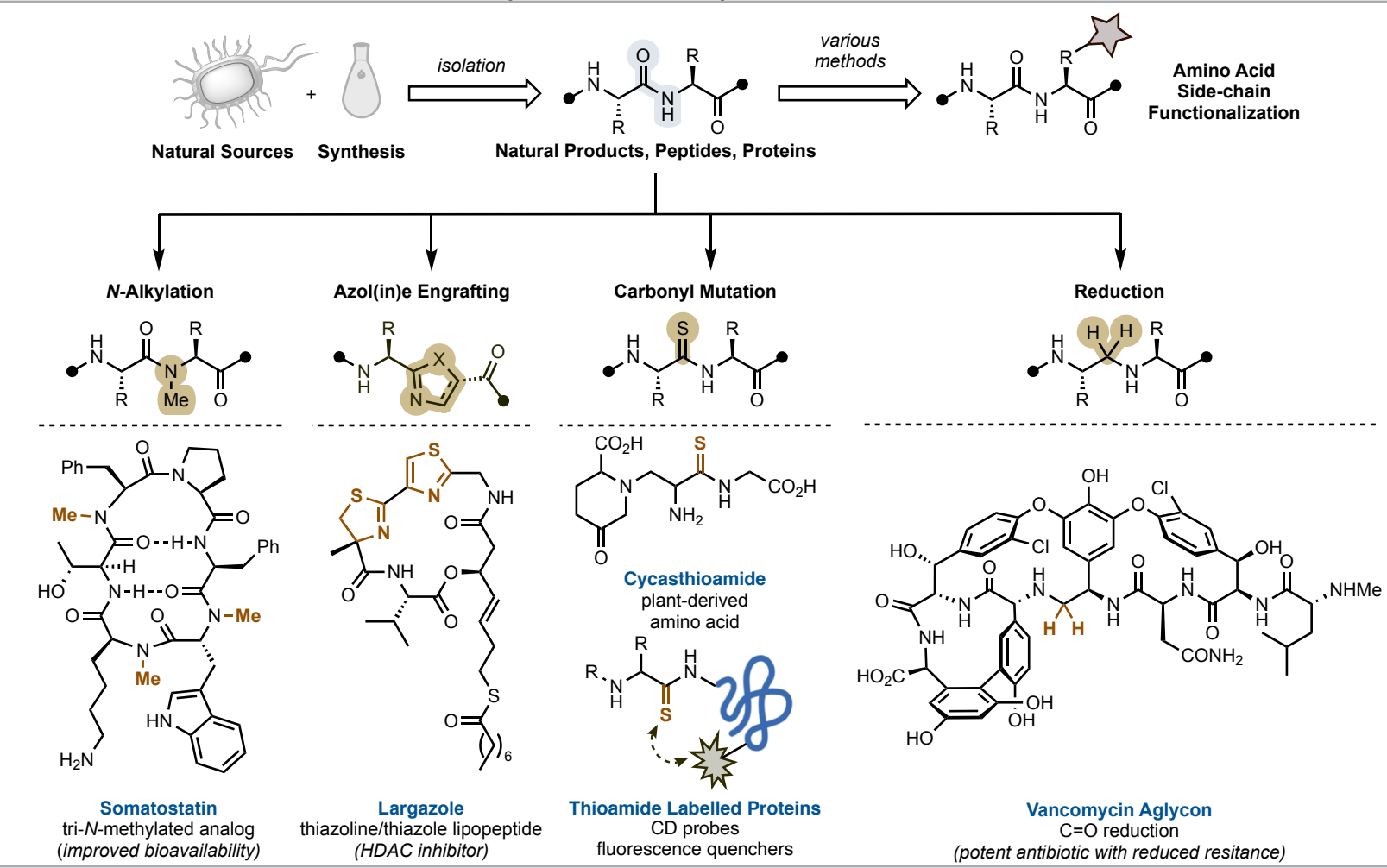

B. Strategies in the Synthesis of Post-translationally Modified Peptides

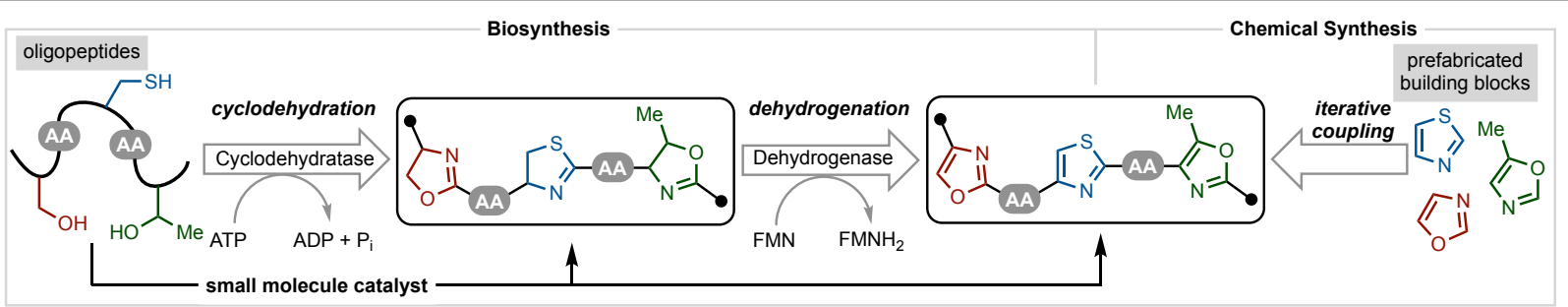

\section{Oxazolines as Activated Amides}

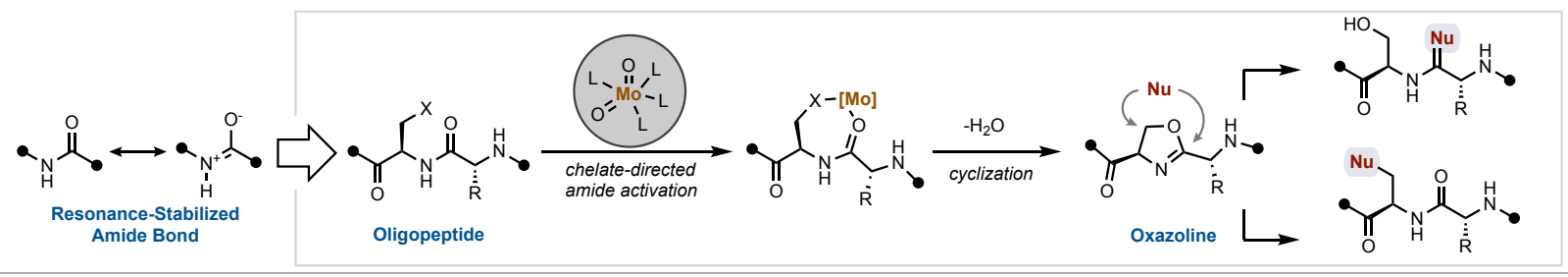

Figure 1. Overview of the conceptual framework for site-selective amide functionalization. 


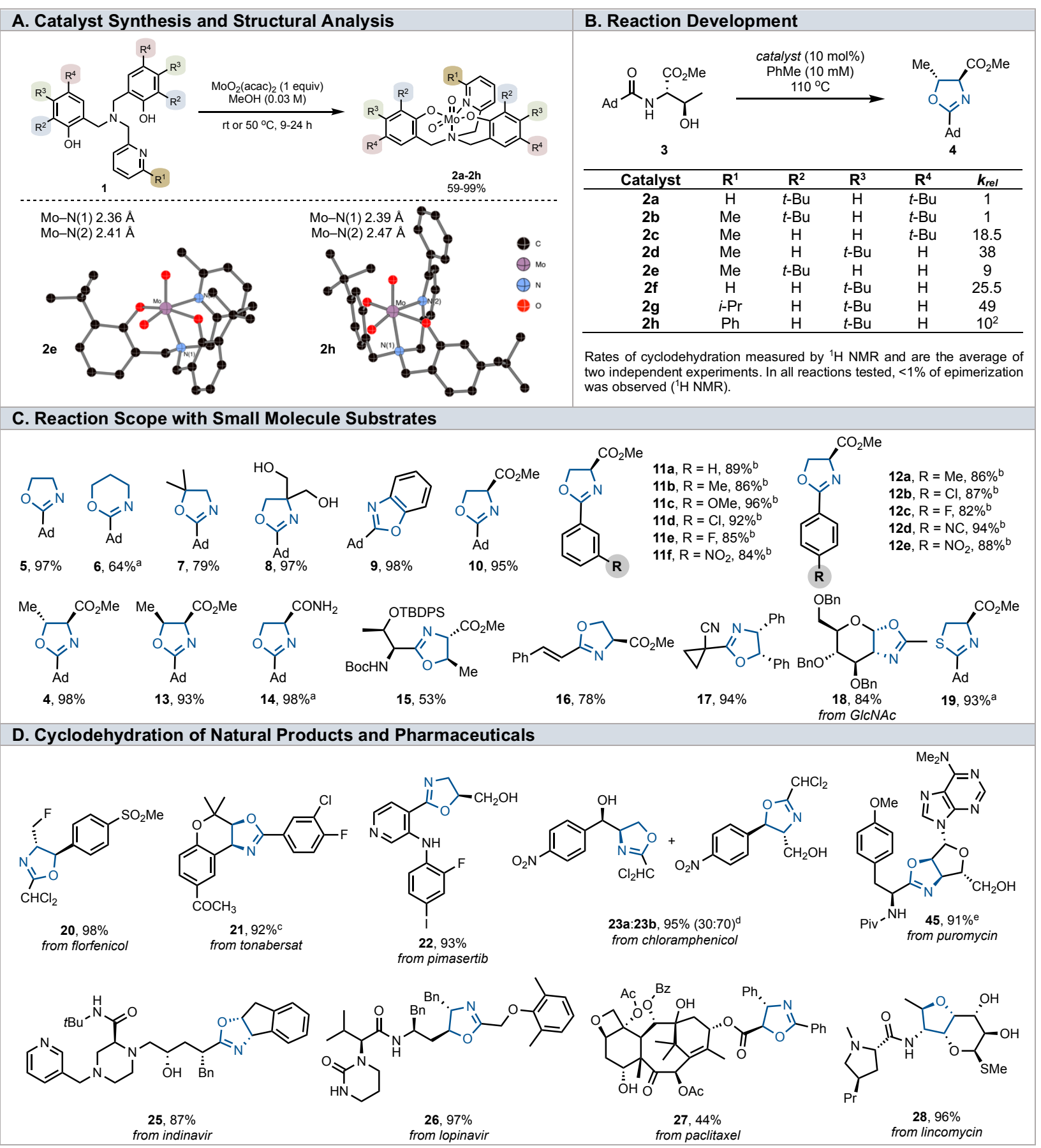

Figure 2. Catalyst identification and scope of $\mathrm{Mo}(\mathrm{VI})$-catalyzed cyclodehydration. General conditions: substrate $(10 \mathrm{mM}), 2 \mathrm{~h}(1 \mathrm{mM})$, PhMe, reflux. ${ }^{a}$ Reaction run in $\mathrm{PhCl}$. ${ }^{b}$ Reaction run with $5 \mathrm{mM}$ of the substrate. ${ }^{\circ}$ Reaction run in $\mathrm{PhCl}$ and $20 \mathrm{~mol} \%$ of $\mathbf{2 h}$. ${ }^{\mathrm{d}} \mathrm{PhMe}: 1,4$-dioxane (9:1) used as a solvent. ${ }^{e}$ Reaction run with $15 \mathrm{~mol} \%$ of $\mathbf{2 h}$. Abbreviations: $A c=a c e t y l ; A d=1$-adamantyl; $B n=b e n z y l ; B o c=$ tert-butoxycarbonyl; $t$-Bu=tert-butyl; $\mathrm{Bz}=$ benzoyl; $\mathrm{Me}=$ methyl; $\mathrm{Ph}=$ phenyl; $\mathrm{Piv}=$ pivaloyl; $\mathrm{Pr}=1$-propyl; $i$-Pr=2-propyl; TBDPS=tertbutyldiphenylsilyl. 


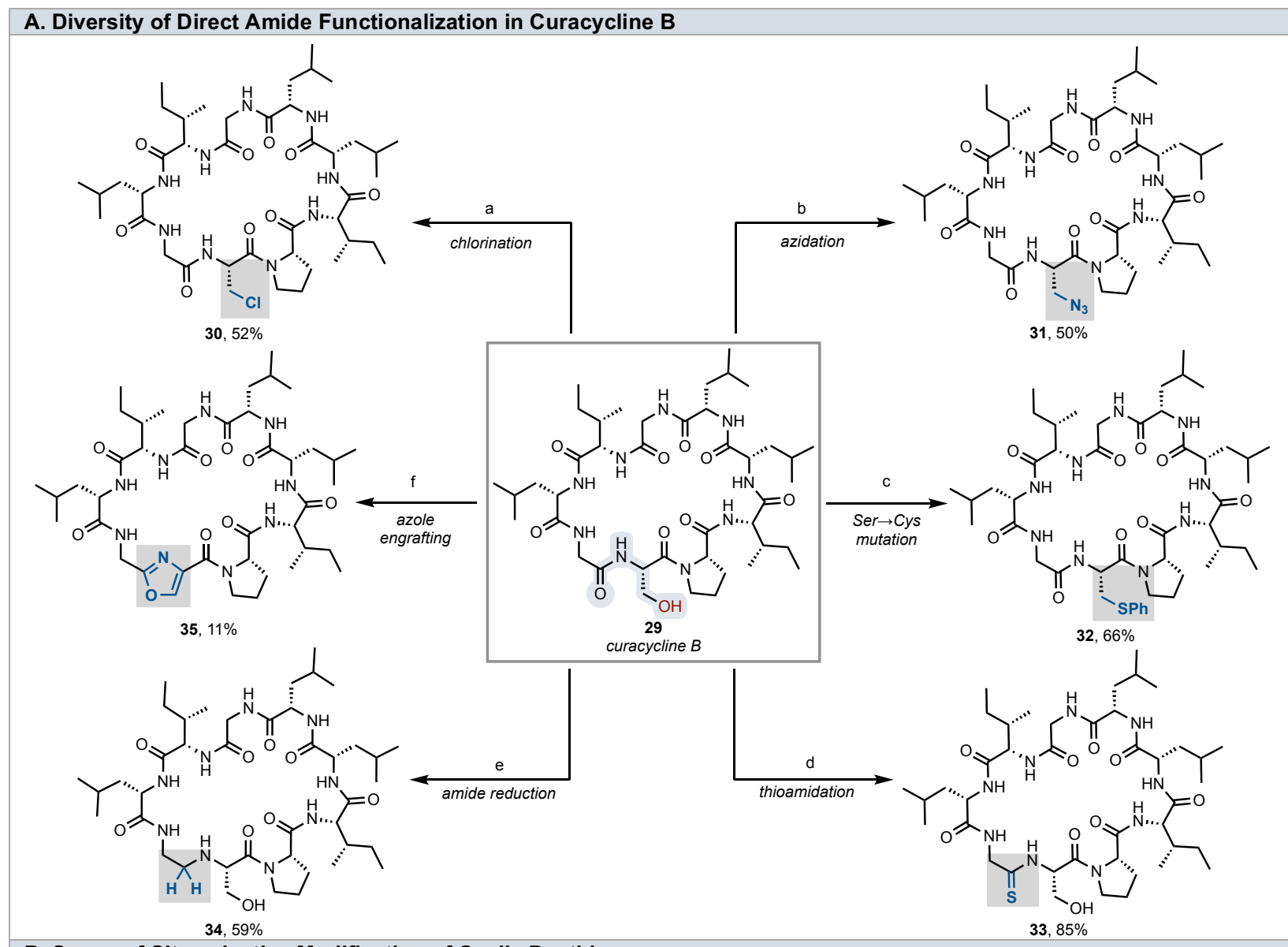

B. Scope of Site-selective Modification of Cyclic Peptides

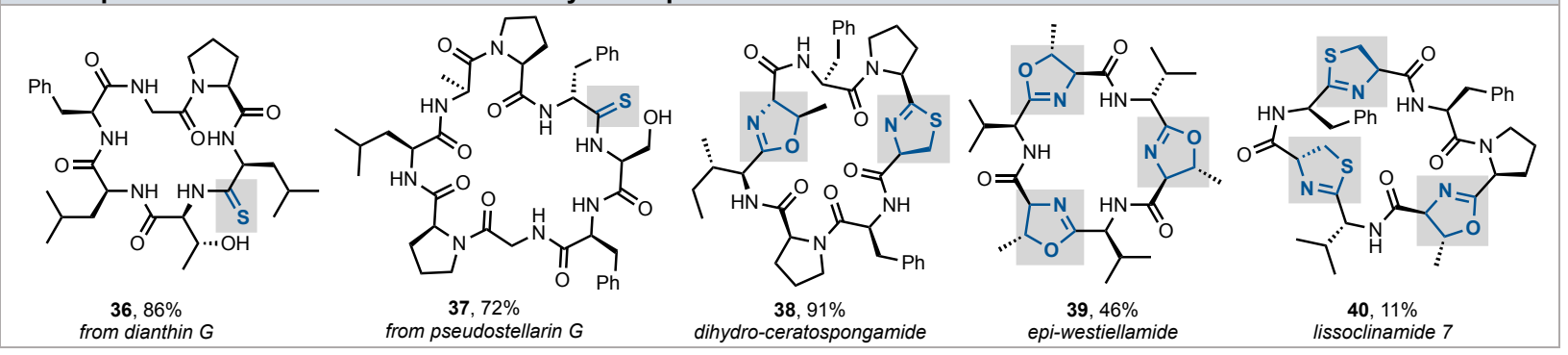

Figure 3. Site-selective amide functionalization of cyclic peptides. A. Reaction conditions: curacycline $B$ (1 $\mathrm{mM}$ ), $\mathbf{2 h}(1 \mathrm{mM}), \mathrm{PhCl}$, reflux, $3 \mathrm{~d}$ then (a) TMSCl, $\mathrm{MeOH}$, 1,4-dioxane (1:9), $60{ }^{\circ} \mathrm{C}, 24 \mathrm{~h}$; (b) $\mathrm{TMSN}_{3}, \mathrm{BF}_{3}$ $\mathrm{Et}_{2} \mathrm{O}, \mathrm{MeOH}-1,4$-dioxane (1:9), $70{ }^{\circ} \mathrm{C}, 15 \mathrm{~h}$; (c) $\mathrm{PhSH}, \mathrm{MeOH}$, reflux, $36 \mathrm{~h}$; (d) $\mathrm{H}_{2} \mathrm{~S}, \mathrm{Et}_{3} \mathrm{~N}-\mathrm{MeOH}$ (1:2); (e) $\mathrm{NaBH}_{3} \mathrm{CN}, \mathrm{AcOH}, 40^{\circ} \mathrm{C}$; (f) $\mathrm{MnO}_{2}, 1,4$-dioxane, $110^{\circ} \mathrm{C}$. B. Reaction conditions: cyclic peptide (1 mM), $2 \mathrm{~h}$ $(1 \mathrm{mM}), \mathrm{PhCl}$, reflux. ${ }^{a}$ Reaction was run in $\mathrm{PhMe}$ followed by $\mathrm{H}_{2} \mathrm{~S}, \mathrm{Et}_{3} \mathrm{~N}-\mathrm{MeOH}$ (1:2) after cyclization. ${ }^{\mathrm{b}}$ Reaction was treated with $\mathrm{H}_{2} \mathrm{~S}, \mathrm{Et}_{3} \mathrm{~N}-\mathrm{MeOH}(1: 2)$ after cyclization. 
A. Proposed Mechanism of Cyclodehydration

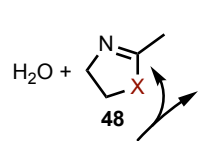<smiles></smiles>

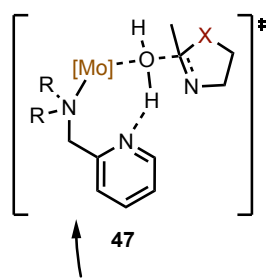

41<smiles>CC(=O)NCC[14CH3]</smiles><smiles>[Y]CCN(C[n+]1ccccc1C)C(C)=O</smiles><smiles>[R]N([R])Cc1ccccc1NCN1CCC([Y])([R])O[Y10]1([H])[H]</smiles>

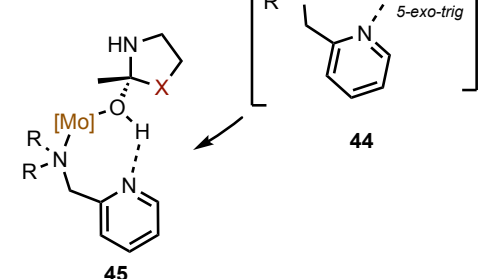

B. Hammett Analysis
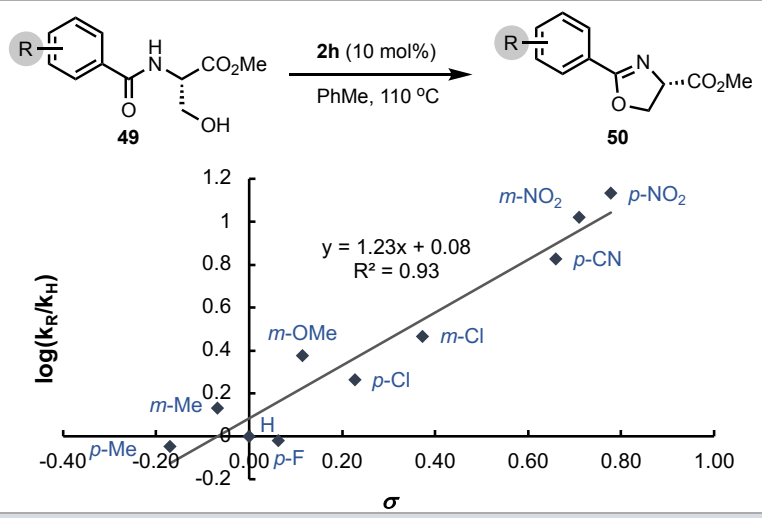

C. Thermodynamic Data for $\mathrm{Z}(\mathrm{N})$ and $\mathrm{Z}(\mathrm{O})$ Conformers

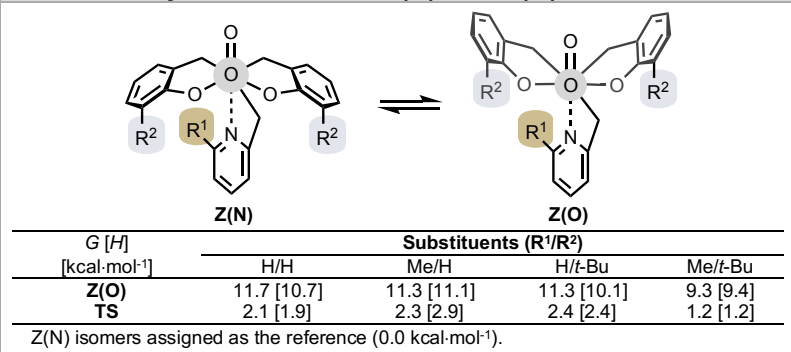

D. Computed Reaction Profile

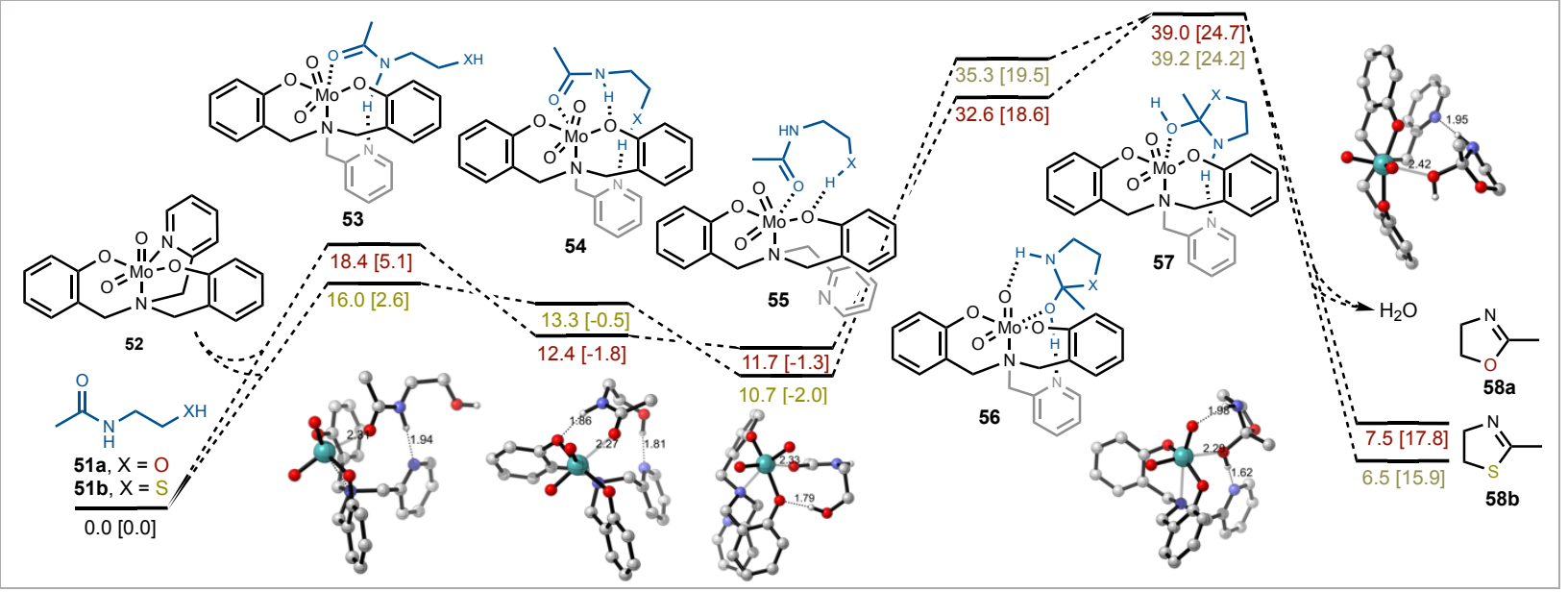

Figure 4. Studies on the mechanism of amide cyclodehydration. Computational analysis of all molybdenum complexes and reaction pathways calculated at B3LYP-GD3/sVTZvpp(SDM toluene)//B3LYP-GD3/SDD$6-31 G^{*}$ (SDM toluene) level of theory. Gibbs free energy and standard enthalpy (in brackets) calculated at $298 \mathrm{~K}$ and given in $\mathrm{kcal} \cdot \mathrm{mol}^{-1}$. 